\title{
Changes in Morphology and Cell Wall Structure that Occur during Growth of Vibrio sp. NCTC4716 in Batch Culture
}

\author{
By D. A. BAKER* AND R. W. A. PARK \\ Microbiology Department, Reading University, Reading $R G$ I $5 A Q$
}

(Received I7 July 1973; revised II March 1974)

\begin{abstract}
SUMMARY
When grown in batch culture in various media Vibrio sp. NCTC4716 displayed a distinct sequence of morphological forms. Organisms occurred as stout, almost straight rods in exponential phase, curved rods (characteristic of Vibrio spp.) in stationary phase, and predominantly as spheres in decline phase. The spheres were formed after growth had ceased due to the depletion of the carbon/ energy source. They were not viable, survival of the culture depending on the few rod forms that remained during the decline phase. The spheres seemingly arose from degradation, but not complete removal, of the peptidoglycan present in the walls. Though spheres contained less nucleic acid and low molecular weight cytoplasmic constituents than did rods, many still possessed an intact cytoplasmic membrane.
\end{abstract}

\section{INTRODUCTION}

Interest in morphology as a feature for identifying vibrios (Park \& Jeynes, 1959; Park, 1961; Davis \& Park, 1962; Morris \& Park, 1971) and in rod to sphere morphogenesis prompted a study of several aspects of morphology of the facultatively anaerobic Vibrio sp. NCTC47I6, an organism similar in physiology and morphology to $V$. cholerae but differing in being of serological O subgroup VI (Gardner \& Venkatraman, 1935) rather than O subgroup I, the only group of vibrios known to cause epidemic cholera. We studied the effect of cultural conditions on morphology, the importance of spheres for survival, and the relationship between rods and spheres with particular reference to changes in the peptidoglycan layer of the cell walls during the rod to sphere transformation.

\section{METHODS}

Organisms. Stock cultures of Vibrio sp. NCTC4716, hereafter termed Vibrio 4716, were maintained on nutrient agar slopes in $\mathrm{I} \mathrm{oz}$ universal screw-cap bottles. The stocks were subcultured every four months, incubated at $30^{\circ} \mathrm{C}$ for $24 \mathrm{~h}$, and then stored at room temperature in the dark. At least two subcultures were made at $24 \mathrm{~h}$ intervals before a culture was used as an inoculum for an experiment.

Media. Nutrient broth contained (g/l demineralized water): peptone (Evans, Speke, Liverpool), 5; Lab Lemco (Oxoid), 5; NaCl, 5; final $\mathrm{pH} 7 \cdot 0$. Nutrient agar was prepared by adding No. 3 agar (Oxoid), $\mathrm{x} \cdot 2 \%(\mathrm{w} / \mathrm{v})$ to the above medium. Casamino acid liquid medium was prepared as described by Finkelstein, Atthasampunna, Chulasamayer \& Charunmethee (1966). Non-nutrient mineral salts medium was the mineral base of Stanier,

\footnotetext{
* Present address: Watney Mann and Truman Brewers Ltd, Mortlake Brewery, London SWI4 7ET.
} 
Palleroni \& Doudoroff (I966) solidified with Ionagar No. 2 (Oxoid), I \% (w/v). Ringer's solution was prepared to $\frac{1}{4}$ strength using tablets (BR 52, Oxoid).

Shake flask cultures. Nutrient broth and Casamino acid liquid medium were usually dispensed in $300 \mathrm{ml}$ amounts in I 1 Erlenmeyer flasks and inoculated with a $\mathrm{I} \%(\mathrm{v} / \mathrm{v})$ inoculum of an early stationary phase culture grown in the corresponding medium. Cultures were incubated on an orbital shaker ( $200 \mathrm{rev} . / \mathrm{min}$ around a circle of $30 \mathrm{~mm}$ diameter) at $30{ }^{\circ} \mathrm{C}$.

Measurement of growth. Viable organisms were counted as colonies after $24 \mathrm{~h}$ at $30^{\circ} \mathrm{C}$ on nutrient agar plates, inoculated by spreading $0.1 \mathrm{ml}$ of appropriate dilutions of cultures in Ringer's solution. Total counts were obtained by using the Breed smear method (Harrigan \& McCance, 1966). Estimations of population size by extinction were made by using an EEL colorimeter (Evans Electroselenium, Halstead, Essex) with a blue filter.

Slide culture. About $100 \mathrm{~mm}^{2}$ of agar was cut from a thin nutrient agar plate poured in a glass Petri dish, transferred to a sterile slide and inoculated with a small drop of nutrient broth culture, diluted if necessary in fresh nutrient broth. A sterile coverslip, larger than the agar, was pressed on to its surface and the culture completely enclosed by sealing the edges with molten petroleum jelly.

Separation by zonal centrifuging of spheres from rods in decline phase cultures. In order to obtain spheres we incubated cultures until about $95 \%$ of the organisms were spherical and then, for most experiments, simply used all the organisms present. This generally required incubation of the culture for $72 \mathrm{~h}$ in shaken flasks. However, for some work, particularly that on peptidoglycan, the following separation procedure was used. A sucrose gradient ( $475 \mathrm{ml}$, with concentration changing linearly from 10 to $40 \%$, w/v, sucrose in $\frac{1}{4}$ strength Ringer's solution), followed by a cushion of $60 \%(\mathrm{w} / \mathrm{v})$ sucrose $(75 \mathrm{ml})$, was loaded into a moving zonal rotor (MSE series BXIV, Manor Royal, Crawley, Sussex) by means of a gradient former. A bacterial suspension from a decline phase Casamino acid culture was made in Casamino acid liquid medium ( $100 \mathrm{ml}$ containing approx. $50 \mathrm{~g}$ wet wt bacteria), loaded into the rotor and centrifuged at $2500 \mathrm{~g}$ for $30 \mathrm{~min}$, after which the material was collected in $20 \mathrm{ml}$ fractions using a fraction collector. The spheres were less dense than the rods. The first 14 fractions from the rotor were combined, the organisms harvested by centrifuging and washed in Ringer's solution. There was about I rod per I000 spheres in this preparation.

Treatment of bacteria with lysozyme and EDTA solutions. The method used was based on that of Repaske (1958). Organisms were treated with 0.017 M-tris buffer $\mathrm{pH} 7.5$ containing lysozyme $(200 \mu \mathrm{g} / \mathrm{ml})$ and EDTA $(500 \mu \mathrm{g} / \mathrm{ml})$.

Estimation of low molecular weight cytoplasmic components and nucleic acids. Organisms (60 mg wet wt) were treated with $5 \mathrm{ml} 0.5 \mathrm{M}$-perchloric acid (PCA) at $4{ }^{\circ} \mathrm{C}$ for $30 \mathrm{~min}$ to extract low molecular weight cytoplasmic compounds such as amino acids and nucleotides. After centrifuging, the supernatant fluid (termed the cold extract) was stored and the organisms treated with $10 \mathrm{ml} 0.5 \mathrm{M}-\mathrm{PCA}$ at $70^{\circ} \mathrm{C}$ for $30 \mathrm{~min}$. After centrifuging, the supernatant fluid (termed the hot extract) which contained the nucleic acids was removed and stored. The relative amounts of low molecular weight nucleotide compounds and of nucleic acids from various organisms were estimated by measuring the extinction at $260 \mathrm{~nm}$.

A more accurate determination of nucleic acids was made as follows: Organisms grown in Casamino acid liquid medium were washed and then resuspended in $\frac{1}{4}$ strength Ringer's solution to give a known concentration of about $50 \mathrm{mg}$ wet $\mathrm{wt} / \mathrm{ml}$. A sample (I ml) of the bacterial suspension was added to $9 \mathrm{ml} \mathrm{0.2} \mathrm{M-PCA}$ and left overnight at $4{ }^{\circ} \mathrm{C}$. The organisms treated with PCA were centrifuged and the supernatant fluid (cold extract) discarded. The 


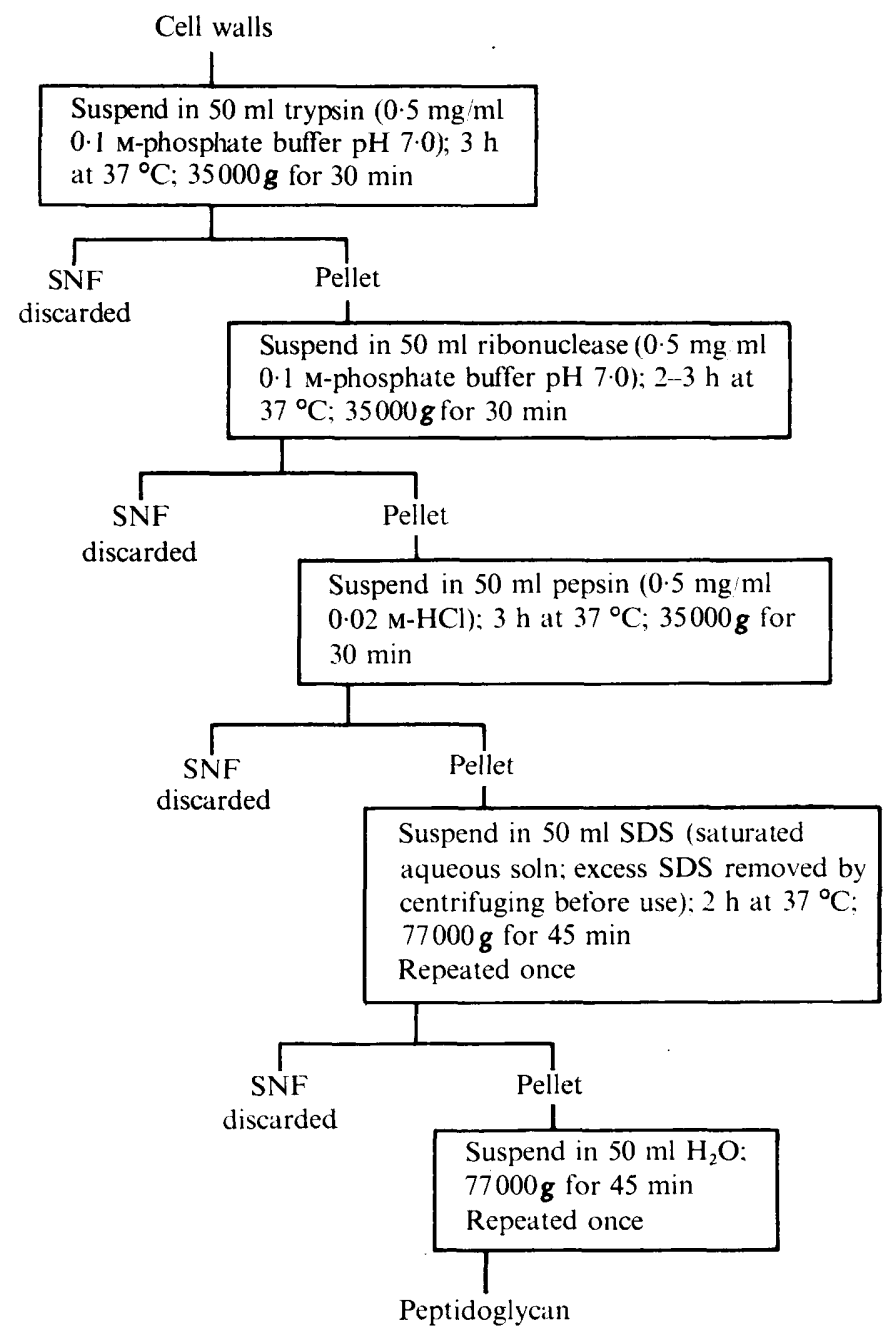

Fig. I. A summary of the isolation procedure for peptidoglycan. Approximately I g wet wt or $200 \mathrm{mg}$ dry wt cell walls were used. SNF, supernatant fluid; SDS, sodium dodecyl sulphate.

pellet was resuspended to $5 \mathrm{ml}$ in $0.5 \mathrm{M}$-PCA and heated for 20 min at $70{ }^{\circ} \mathrm{C}$. The suspension was chilled in ice, centrifuged and the supernatant fluid (hot PCA extract) decanted into a graduated test tube. The hot PCA extraction was repeated and the two hot PCA extracts combined. DNA and RNA were estimated by the methods of Burton (I956) and Morse \& Carter (1949), respectively, using salmon sperm DNA and yeast RNA (sodium salt) as standards.

Preparation of bacterial walls. Bacteria ( $\mathrm{I} 3$ to $17 \mathrm{~g}$ wet $\mathrm{wt}$ ) were broken in a Braun Homogenizer, and washed twice by centrifuging with distilled water $\left(3^{\circ} \mathrm{C}\right)$ at $35000 \mathrm{~g}$ for I 5 min. The upper layer of the final pellet, consisting mainly of bacterial walls, was scraped with a spatula from the lower layer of unbroken organisms and debris which were discarded. The walls were then cleaned by at least six successive washes in $60 \mathrm{ml} \mathrm{I} \mathrm{M-NaCl}\left(3^{\circ} \mathrm{C}\right)$ followed by at least six successive washes in $60 \mathrm{ml}$ demineralized water $\left(3^{\circ} \mathrm{C}\right)$. After each centrifugation the walls were again scraped from any unbroken organisms deposited at the 
base of the pellet. The walls were freeze-dried and stored in a desiccator at room temperature.

Preparation of peptidoglycan. Organisms were broken and harvested as described above, but washed only twice in $\mathrm{I} \mathrm{M}-\mathrm{NaCl}\left(3^{\circ} \mathrm{C}\right)$ and once in demineralized water $\left(3^{\circ} \mathrm{C}\right)$. Autolytic enzymes were inactivated by suspending the walls in the minimum amount of water in a $100 \mathrm{ml}$ centrifuge tube and shaking for $\mathrm{IO} \mathrm{min}$ in a boiling water bath. The suspension was diluted $\mathrm{I}: 9(\mathrm{v} / \mathrm{v})$ with water, centrifuged at $35000 \mathrm{~g}$ for $\mathrm{I} 5 \mathrm{~min}$, and washed once with water. When pellets consisting of walls overlying unbroken organisms and debris were apparent, the upper layer only was collected. A method based on the procedure of Schocher, Bayley \& Watson (1962) for the isolation of peptidoglycan from cell walls was used (Fig. I). The purified peptidoglycan, a clear gel, was suspended in a little distilled water, freeze-dried and stored in a desiccator at room temperature.

Analysis of peptidoglycan. (i) Amino acid composition. Accurately weighed samples (approx. $\mathrm{r} \mathrm{mg}$ ) of peptidoglycan were hydrolysed with $2 \mathrm{ml} 6 \mathrm{M}-\mathrm{HCl}$ for $16 \mathrm{~h}$ at $105{ }^{\circ} \mathrm{C}$. The hydrolysed samples were dried by rotary evaporation, redissolved in $100 \mu \mathrm{l}$ water and stored at $4{ }^{\circ} \mathrm{C}$. The paper chromatography method of Mandelstam \& Rogers (1959) was used for the quantitative estimation of the amino acids.

(ii) Amino sugar composition. Accurately weighed samples (approx. I mg) of peptidoglycan were hydrolysed with $2 \mathrm{ml} 4 \mathrm{M}-\mathrm{HCl}$ for $2 \mathrm{~h}$ at $100{ }^{\circ} \mathrm{C}$. The hydrolysed samples were dried by rotary evaporation, redissolved in $2 \mathrm{ml}$ water and stored at $4{ }^{\circ} \mathrm{C}$. Samples $(0.5 \mathrm{ml})$ were assayed for total amino sugars by the Elson \& Morgan (1933) reaction using the method of Rondle \& Morgan (I955) with glucosamine as standard.

(iii) Assessment of the degree of crosslinking between peptide subunits. The degree of peptide crosslinking was estimated from the ratio of linked to free amino groups on the Dcarbon of mesodiaminopimelic acid (DAP). Free amino groups were estimated by reacting the peptidoglycan with r-fluoro 2,4-dinitrobenzene (FDNB) using a method based on that of Ingram \& Salton (1957). An accurately weighed sample (about $2 \mathrm{mg}$ ) of peptidoglycan was incubated at $37^{\circ} \mathrm{C}$ overnight with $2 \mathrm{mg}$ sodium carbonate and $200 \mu \mathrm{l} \mathrm{FDNB}(5 \%$, $\mathrm{v} / \mathrm{v}$, solution in ethanol). After incubation, $0.2 \mathrm{ml} 6 \mathrm{M}-\mathrm{HCl}$ and $\mathrm{I} \mathrm{ml}$ water were added and excess FDNB was extracted with three $2 \mathrm{ml}$ portions of ether. The ether layers were discarded and the remaining ether was evaporated from the reaction mixture using a rotary evaporator. Then $\mathrm{r} \cdot 4 \mathrm{ml}$ conc. $\mathrm{HCl}$ was added to give a final concentration of approximately $6 \mathrm{M}-\mathrm{HCl}$ and the FDNB-treated peptidoglycan hydrolysed for $16 \mathrm{~h}$ at $105^{\circ} \mathrm{C}$. The hydrolysed sample was diluted with $14 \mathrm{ml}$ water and treated with three $10 \mathrm{ml}$ portions of ether to extract the ether-soluble dinitrophenyl (DNP) amino acids. These were discarded. The water layer, which contained unreacted amino acids (i.e. those that had no free amino groups) together with water-soluble DNP-amino acids (e.g. mono-DNP-DAP), was dried, redissolved in $100 \mu \mathrm{l}$ water and stored in the dark. This solution was applied ( $25 \mu \mathrm{l})$ to No. 4 chromatography paper (Whatman, Balston Ltd, Maidstone, Kent) which previously had been sprayed with $0.05 \mathrm{M}$-phthalate buffer $\mathrm{pH} 6.0$ and dried. The chromatogram was developed in the dark at $24{ }^{\circ} \mathrm{C}$ by the descending method using as solvent tertiary amyl alcohol saturated with $0.05 \mathrm{M}$-phthalate buffer pH 6.0 (Blackburn \& Lowther, 195I). The chromatogram was developed for approximately $\mathrm{I} O \mathrm{~h}$ and the paper dried at room temperature in the dark. Mono-DNP-DAP spots were cut out and eluted in $3 \mathrm{ml}$ aqueous sodium bicarbonate $(\mathrm{I} \%, \mathrm{w} / \mathrm{v})$ and the absorption at $360 \mathrm{~nm}$ determined. A $70 \%$ recovery of monoDNP-DAP after hydrolysis in the presence of other peptidoglycan material was assumed (Ingram \& Salton, 1957) and the $\epsilon_{360}$ of mono-DNP-DAP was taken to be $\mathrm{I} \cdot 7 \times 10^{4} 1 / \mathrm{mol} / \mathrm{cm}$ (Salton, 196I). The DAP involved in peptide crosslinking in the peptidoglycan did not form 
DNP derivatives and remained at the origin of chromatogram developed in the phthalatetertiary amyl alcohol system. This DAP was estimated by the method of Work (1957) using standard quantities of DAP (o to $20 \mu \mathrm{g}$ ) as reference. Alanine and glutamic acid were present at or near the origin but these amino acids, in the concentrations at which they were present, had no effect on the DAP assay (Work, 1957).

(iv) Assessment of glycan chain length. The ratio of reducing-terminal amino sugar to total amino sugars in the glycan chains was determined. To estimate reducing-terminal amino sugars an accurately weighed sample $(0.5$ to $\mathrm{I} \cdot 0 \mathrm{mg})$ of peptidoglycan was suspended in I $\mathrm{ml}$ water and reducing power estimated by the method of Nelson (1944). To estimate total reducing power an accurately weighed peptidoglycan sample (approx. $\mathrm{I} \cdot 0 \mathrm{mg}$ ) was hydrolysed as for amino sugar composition, dried, and redissolved in $2 \mathrm{ml}$ water. This aqueous solution was diluted with water ( $\mathrm{I}: \mathrm{I} 4, \mathrm{v} / \mathrm{v}$ ) and samples ( $\mathrm{I} \mathrm{ml}$ ) assayed by the Nelson (1944) method. Before calculating the chain lengths, the values obtained for total reducing power were corrected for a $17 \%$ loss of reducing power which was found to occur during hydrolysis.

Electron microscopy. Organisms were harvested, washed once in saline $(0.85 \%)$ and fixed with osmium tetroxide. The fixed specimens were dehydrated with alcohol followed by propylene oxide and embedded in Araldite. Sections were cut on a Huxley microtome, stained with lead citrate, washed with water and dried. Sections were examined with an AEI EM6 electron microscope.

\section{RESULTS}

\section{Growth and changes in morphology during batch cultivation}

Colony counts of liquid cultures were used to define the phases of growth. Thus, we defined the exponential phase as the period during which colony counts increased exponentially with time (e.g. up to about $8 \mathrm{~h}$ in our shake flask cultures), the stationary phase as the period during which the colony counts were virtually constant (e.g. 8 to $48 \mathrm{~h}$ in our shake flask cultures) and the decline phase as the period when the colony counts decreased.

The morphology of the organisms was different in the different growth phases. During exponential phase the organisms were stout rods, during stationary phase they were slender, curved and S-shaped rods, and during the decline phase an increasing percentage of the organisms were spherical (Fig. 2). Total counts, viable counts, counts of rods (i.e. all forms but spheres) and counts of spheres indicated that each sphere was derived from a single rod and could not reproduce. The decrease in viable count occurred before spheres became dominant, implying that 50 to $75 \%$ of the rods, as well as all the spheres, could not reproduce. Onset of stationary phase in our cultures was due to depletion of a carbon and energy source rathe1 than to depletion of other nutrients or to accumulation of inhibitory metabolites. Thus, addition of sucrose to cultures in stationary phase allowed resumption of growth. Work on this aspect was reported in detail by Baker (I97I).

\section{Relationships between cultural conditions and morphology, as revealed by slide culture}

Using a microscope incubation cabinet, slide cultivation on nutrient agar of an inoculum from a declining nutrient broth culture confirmed that some rods, but no spheres, were capable of reproduction (Fig. 3). Similar results were obtained with cultivation on L-form agar (Iannetta \& Wedgwood, I967), suggesting that the spheres did not differ from the rods only by lacking the rigid component of their wall. Slide cultivation of rods from stationary 


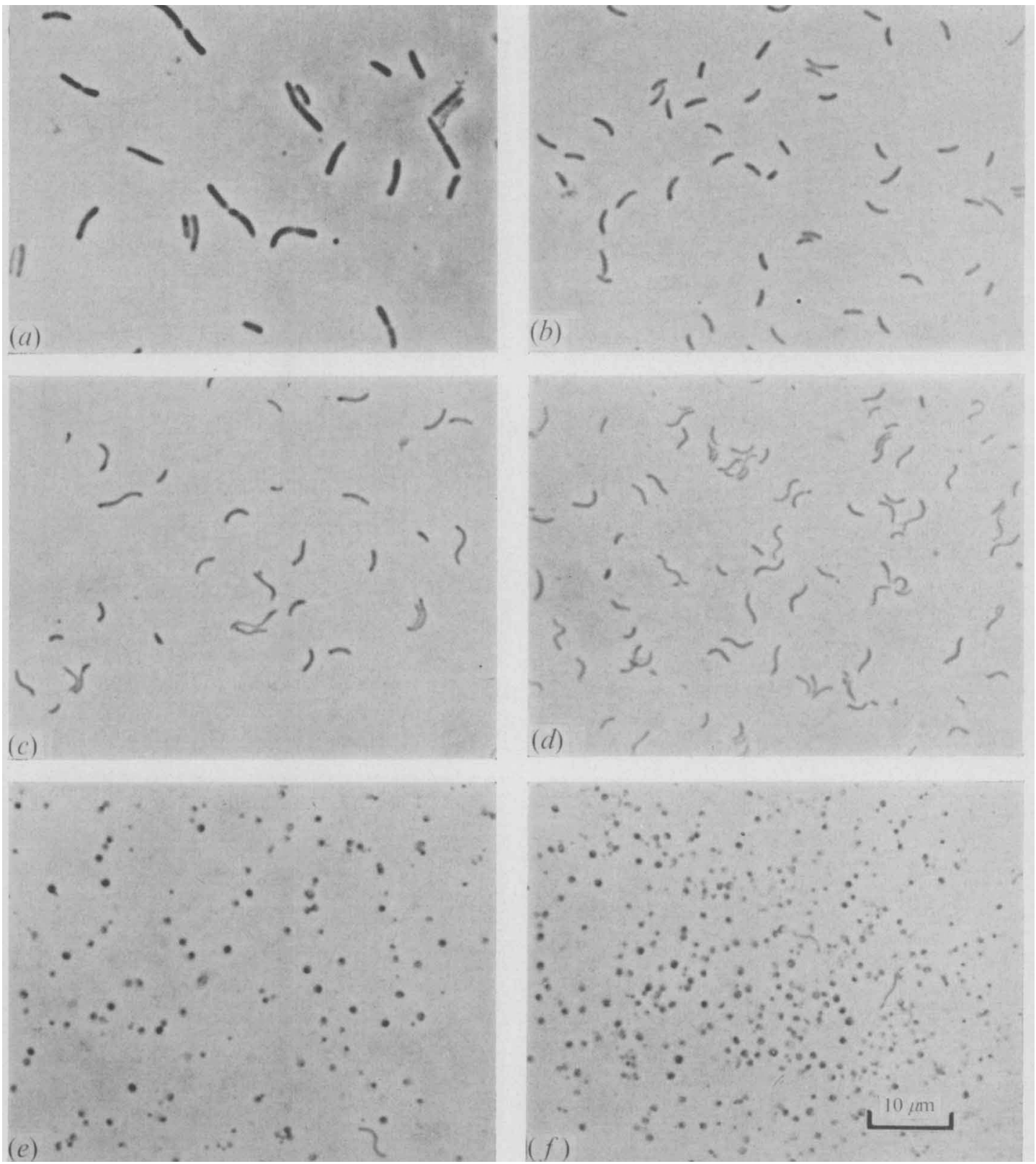

Fig. 2. Vibrio sp. NCTC4716 growing in Casamino acid liquid medium, shaken at $30{ }^{\circ} \mathrm{C}$, and examined by phase contrast microscopy $(a)$ during exponential phase, $(b)$ at the onset of the stationary phase, $(c)$ during the stationary phase, $(d)$ at the onset of decline, $(e, f)$ during decline. 

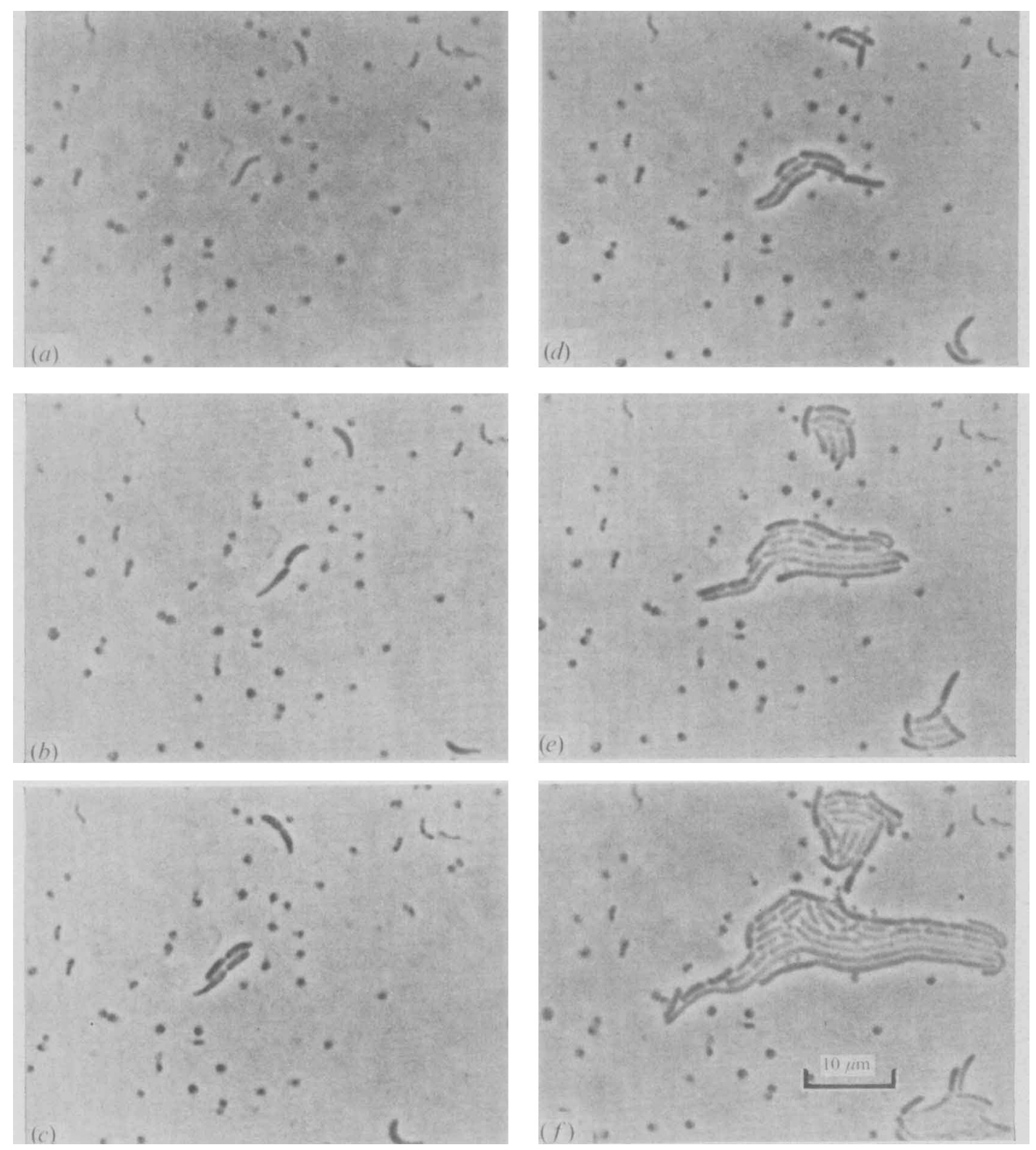

Fig. 3. Slide culture of Vibrio sp. NCTC4716 on nutrient agar at $30{ }^{\circ} \mathrm{C}$ examined by phase contrast microscopy. Inoculum from a culture (a) early in the decline phase, (b) after $3 \mathrm{~h},(c)$ after $5 \frac{1}{2} \mathrm{~h}$, $(d)$ after $7 \mathrm{~h} .(e)$ after $8 \frac{1}{2} \mathrm{~h},(f)$ after $9 \frac{1}{2} \mathrm{~h}$. Some of the rods but none of the spheres were capable of growth. 
phase on a non-nutrient mineral salts medium showed that in the absence of a carbon/ energy source some rods were capable of cell division - the 'shift-down' phenomenon (Mandelstam \& McQuillen, I968) - while others became spherical due to loss of rigidity of the cell wall (Fig. 4). Thus spheres were formed from rods under starvation conditions which could be regarded in some ways as comparable with the conditions associated with sphere formation in batch culture. The reason for the difference between rods which divided and rods which became spherical was not determined.

\section{Evidence of an intact cytoplasmic membrane in spheres}

Decline phase spheres were capable of osmotic response and so were considered to have an intact cytoplasmic membrane. Thus, after suspension for $12 \mathrm{~h}$ in $45 \%$ sucrose solution spheres were smaller than spheres suspended for the same period in Ringer's solution, which in turn were smaller than spheres suspended in distilled water. In another experiment lysis or leakage was determined by measuring the release of $260 \mathrm{~nm}$ absorbing material (nucleic acids and/or nucleotides, etc.). Spheres suspended in water released, by lysis of some of the cells, more $260 \mathrm{~nm}$ absorbing material than did rod forms suspended in water (Fig. 5). The rods leaked whether they were suspended in water or Ringer's solution; there was slightly more leakage in water. Such leakage products were probably low molecular weight 'pool' metabolites, e.g. nucleotides and amino acids, although some lysis might have occurred. Spheres suspended in Ringer's solution showed the least leakage of $260 \mathrm{~nm}$ material, possibly because they did not lyse in this solution and, being senescent, possessed only small cytoplasmic pools.

\section{Absorbing material and individual nucleic acids in the rods and spheres}

A comparison of amounts of $260 \mathrm{~nm}$ absorbing material in cold and hot perchloric acid extracts from rods and spheres confirmed that spheres had less low molecular weight cytoplasmic components and showed that they had less nucleic acid than the rods (Table I). The spheres had much less RNA than the rod forms (Table r). As late stationary phase rods had markedly less RNA than had exponential phase rods it could be that some of the RNA had been degraded and metabolized during stationary phase (Strange, Dark \& Ness, I96I), a process, together with leakage, that would have continued during the decline. From this data it appeared that little, if any, DNA had been lost from the spheres but examination of the media indicated that much DNA (or derivatives) had leaked.

\section{Envelopes from the rods and the spheres}

The formation of spheres in cultures of Vibrio 4716 appeared to be an autolytic process associated with death. To understand more about the change in morphology we studied in detail the peptidoglycan from the rods and spheres.

Rod peptidoglycan. The wall of Vibrio 4716 accounted for $12 \%$ of the dry weight in exponential phase and between 24 and $29 \%$ of the dry weight in the stationary phase (Table 2). The amount of peptidoglycan (as a proportion of the wall dry wt) remained reasonably constant, accounting for between 12 and $16 \%(\mathrm{w} / \mathrm{w})$. The peptidogylcan had DAP, alanine and glutamic acid in approximate molar ratios of $I: 2: \mathrm{I}$ and in this respect resembled other Gram-negative bacteria (Ghuysen, 1968). Apart from these three major peptidoglycan amino acids, small amounts of other amino acids, particularly serine, glycine and aspartic acid, were also present in the peptidoglycan preparations. Other layers of the Gram-negative wall are thought to be linked to the peptidoglycan (Braun \& Schwartz, 1969; Braun \& Rehn, 1969) but it is not known if these associated amino acids in the Vibrio 

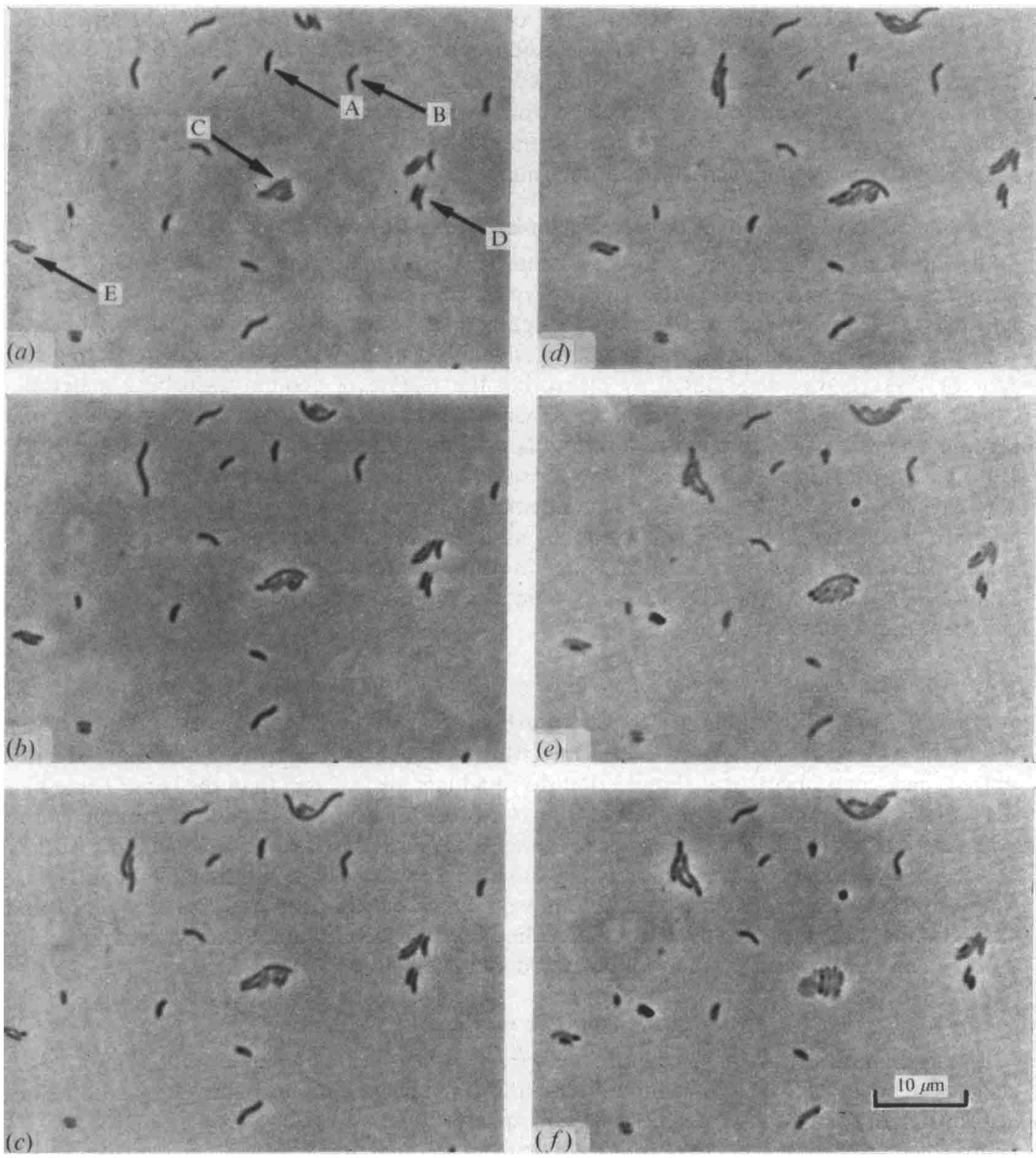

Fig 4. For legend, see following page.

peptidoglycan were covalently linked to the peptidoglycan and involved in linkage to other wall components. Between 44 and $54 \%$ of the DAP from the rod forms was involved in peptide crosslinking. During estimations of the degree of crosslinking a water soluble DNP derivative which ran faster on chromatograms than mono or di-DNP-DAP isomers were isolated. Degradation with ammonia (Lowther, 195I) showed this unknown DNP derivative $\left(R_{F} 0 \cdot 29\right)$ to contain DAP, and indeed the degradation products appeared similar chromatographically to the degradation products of DNP-DAP derivatives. On degradation 

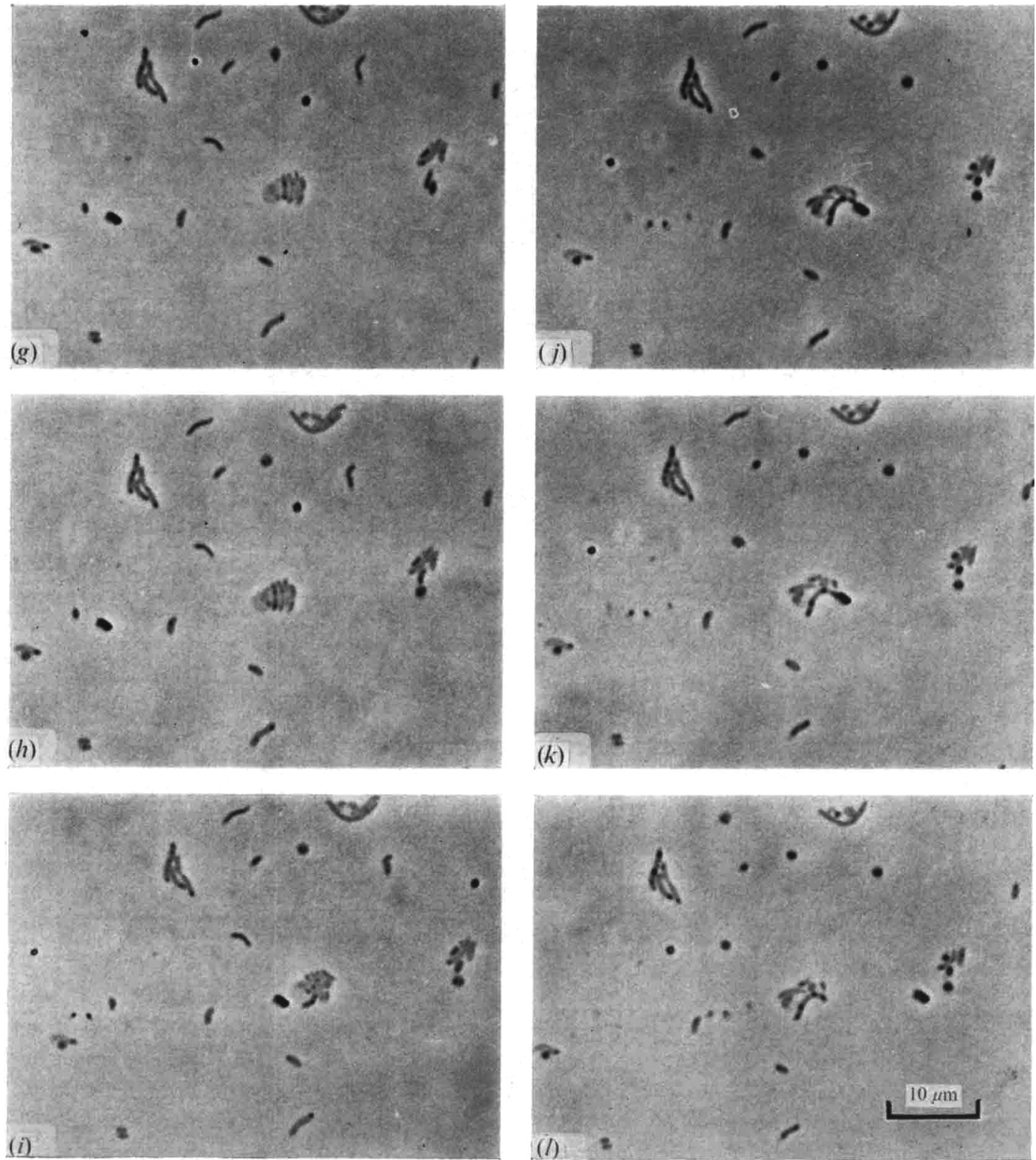

Fig. 4. Slide culture of Vibrio sp. NCTC47I 6 on non-nutrient agar at $30{ }^{\circ} \mathrm{C}$ examined by phase contrast microscopy. Inoculum from a culture $(a)$ in stationary phase, $(b)$ after $1 \frac{1}{2} \mathrm{~h},(c)$ after $5 \frac{1}{2} \mathrm{~h}$, $(d)$ after io h, $(e)$ after $22 \frac{1}{2} \mathrm{~h},(f)$ after $25 \mathrm{~h},(g)$ after $26 \frac{1}{2} \mathrm{~h},(h)$ after $28 \mathrm{~h},(i)$ after $34 \mathrm{~h},(j)$ after $48 \mathrm{~h}$, $(k)$ after $53 \mathrm{~h},(l)$ after $7 \mathrm{I} \mathrm{h}$. Some rods divided to a limited extent while others became spherical due to the loss of rigidity of the cell wall. A, B, C, D and E indicate organisms of particular interest. 


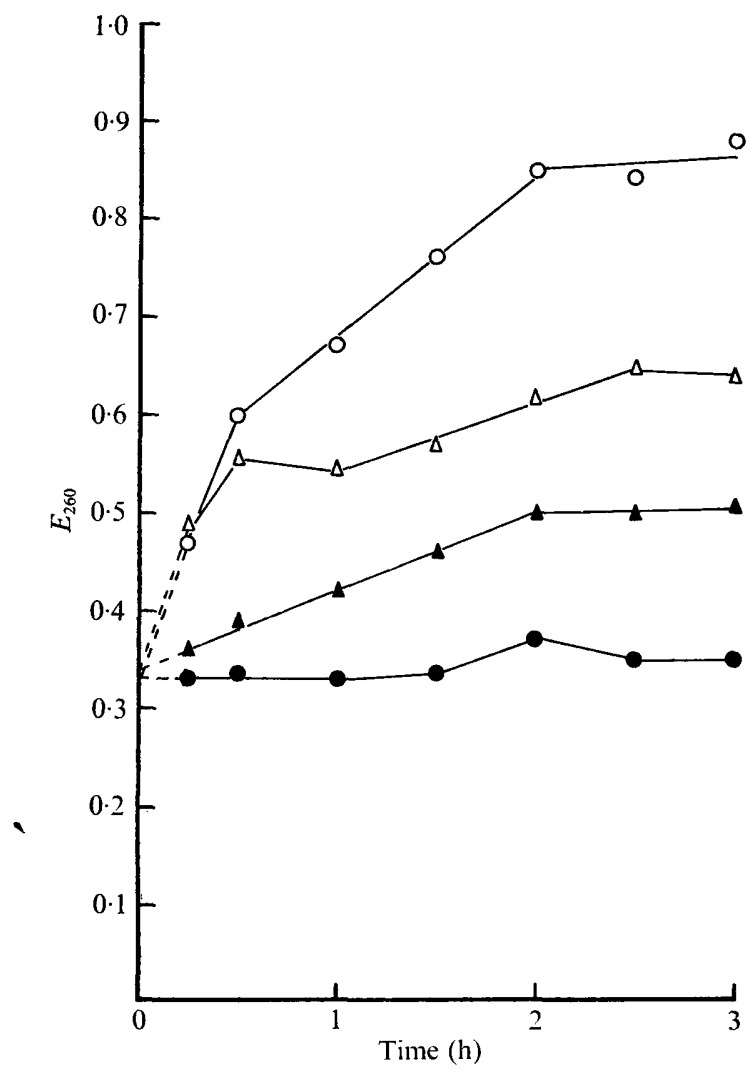

Fig. 5. Release of compounds absorbing at $260 \mathrm{~nm}$ from exponential phase and decline phase organisms of Vibrio sp. NCTC4716 suspended in water or Ringer's solution. The extinctions are of the supernatant fluids after removal of the organisms by centrifugation. The graphs are extrapolated to give zero readings which could not be obtained in practice due to the centrifugation time. $\triangle, \boldsymbol{\Delta}$, Supernatant fluids from exponential phase rods suspended in water and Ringer's solution, respectively; $O$, $O$, supernatant fluids from decline phase spheres suspended in water and Ringer's solution, respectively.

of this unknown DNP derivative no compound corresponding to a mono-DNP derivative, such as occurs when di-DNP-DAP is treated with ammonia, was found. It was assumed in calculating the degree of crosslinking that the unknown DNP derivative was a form of mono-DNP-DAP. The unusual DNP-DAP derivative may have been derived from DAP involved in the linkage of the peptidoglycan to other wall components. The average glycan chain length was determined on a total of I 6 different samples of rod-type peptidoglycan from exponential, late-exponential/early-stationary, mid-stationary and late-stationary phase organisms. It varied from 12 to 60 hexosamine residues, the average length being 35 . The scatter of results for length of glycan chain did not allow a comparison between rodshaped organisms from exponential and stationary phase cultures.

Sphere peptidoglycan. The walls of the decline phase spheres accounted for $35 \%$ of the bacterial dry weight. This value was thought to be high because of the loss of cytoplasmic material which had occurred. Peptidoglycan accounted for only $4 \%$ of the dry weight of the wall. The general chemical composition of the peptidoglycan from the spheres appeared 
Table I. Extinction at $260 \mathrm{~nm}$ of perchloric acid (PCA) extracts of rods and spheres of Vibrio $47 \mathrm{I} 6$ and the nucleic acid content of these organisms

Morphology $\ldots$
Growth phase $\quad \ldots$

Cold PCA extract $\left(E_{260}\right)$

Hot PCA extract $\left(E_{\mathbf{2 6 0}}\right)$

RNA (\% dry wt of organisms)

DNA (\% dry wt of organisms)

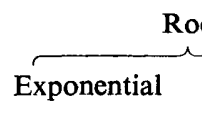

0.64
$3.55^{*}$

$29 \cdot 2$

$2 \cdot 0$
Sphere

Decline

$0 \cdot 28$

$0.3^{*}$

$2 \cdot 7$

$3 \cdot \mathbf{I}$

* Readings from a $20 \%$ dilution multiplied by 5 .

Table 2. Cell walls from rods and spheres of Vibrio 4716

$$
\begin{aligned}
& \text { Morphology } \ldots \\
& \text { Growth phase ... }
\end{aligned}
$$

Cell wall ( $\%$ dry wt of organisms)

Peptidoglycan (\% dry wt of cell wall)

DAP involved in peptide crosslinking ( $\%$ total DAP)

Glycan chain length (no. of hexosamine residues/chain)

$\begin{array}{cccc}\overbrace{\text { Exponential }} & \begin{array}{c}\text { Mid- } \\ \text { stationary }\end{array} & \begin{array}{c}\text { Late- } \\ \text { stationary }\end{array} & \text { Sphere } \\ 16 & 24 & 29 & 35 \\ 54 & 14 & 12 & 4 \\ \underbrace{\text { 12 to 60 (average 35) }}_{12} & 44 & 23 \\ & & \begin{array}{c}6 \text { to 14 } \\ \text { (average 10) }\end{array}\end{array}$

similar to that from the rods, with the exception that there was more of the 'unknown' DAP-containing DNP derivative. The sphere peptidoglycan, however, was less crosslinked than was that from the rod forms. There was a decrease of crosslinked DAP from 44 to $54 \%$ in the rods to $23 \%$ in the spheres, this being indicative of endopeptidase action. In addition, the glycan chain length in six samples of sphere peptidoglycan ranged from 6 to I4, with an average of 10 , and was thus shorter than the glycan chain length in the rod peptidoglycan.

EDTA plus lysozyme affected spheres less than rods, as judged by changes in extinction (Fig. 6). Isolated walls from spheres were also shown by extinction measurements to be more resistant to lysozyme digestion than were walls from rods (Baker, 197I). These observations indicate that the portions of the peptidoglycan that were more sensitive to an endo- $N$ acetylmuramidase had been lost during the rod to sphere transformation. Braun \& Wolff (I970) suggested that some parts of the peptidoglycan should be more sensitive to an endo- $N$ acetylmuramidase than other parts. They found that lysozyme was probably inhibited sterically near the attachment sites of the lipoprotein. The lesser sensitivity to lysozyme of peptidoglycan from the spheres could also be explained if peptide subunits had been lost by amidase action, since lysozyme preferentially attacks peptide-substituted glycan (Tipper, Strominger \& Ensign, 1967; Strominger \& Ghuysen, 1967). There was, however, no evidence of amidase activity in the peptidoglycan of Vibrio 4716 because a similar proportion of the amino sugar residues in both rod and sphere cells carried peptide subunits (Baker, 197I).

Examination of ultrathin sections. The outer membrane, which probably consists of lipo- 


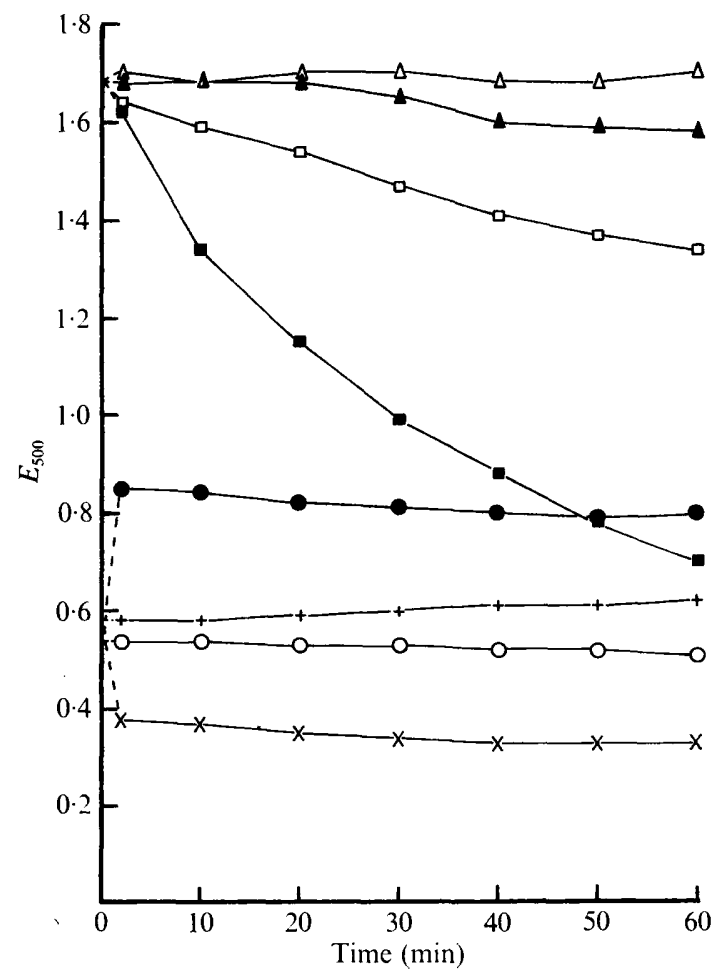

Fig. 6. Effect of lysozyme and EDTA solutions on the extinction at $500 \mathrm{~nm}$ of rods and spheres of Vibrio sp. NCTC4716 suspended in tris buffer. $\triangle$, Rods suspended in tris buffer alone (0.017 M, $\mathrm{pH} 7.5) ; \Delta$, rods plus lysozyme $(200 \mu \mathrm{g} / \mathrm{ml}) ; \square$, rods plus EDTA $(500 \mu \mathrm{g} / \mathrm{ml}) ; \mathbf{m}$, rods plus lysozyme and EDTA. O, Spheres suspended in tris buffer alone; + , spheres plus lysozyme; $x$, spheres plus EDTA; $\bullet$, spheres plus lysozyme and EDTA. Zero readings were not obtained because of the time taken to mix the cell suspensions and measure the extinction. These values have been obtained by extrapolation. Slight flocculation occurred when spheres were suspended in the solution of lysozyme plus EDTA.

polysaccharide and lipoprotein, is clearly visible in sections of rod and spherical vibrios (Fig. 7). The intermediate layers, i.e. peptidoglycan and protein, were not visible in the vibrio sections but can be difficult to detect (Glauert \& Thornley, 1969). The sphere sections differed from the rod sections: the outer membrane of the sphere appeared as though it had straightened and thus expanded away from the cell. In order to do this the outer membrane had either become detached from or remained attached to the intermediate layers but the intermediate layers had fragmented and come away from the cytoplasmic membrane. The cytoplasmic content of the spheres appeared generally to be depleted, consistent with the fact that loss of cytoplasmic contents had occurred.

\section{DISCUSSION}

Spherical forms of Vibrio $47 \mathrm{I} 6$ occurred in our batch cultures when the carbon/energy source was depleted. The spheres were not viable and so appeared to be involution forms serving no function, perpetuation of the species being by the few rod forms remaining in old cultures. The spheres of $V$. cholerae (Henrici, 1925; Mackie, 1929; Braulke, 1933) and of 

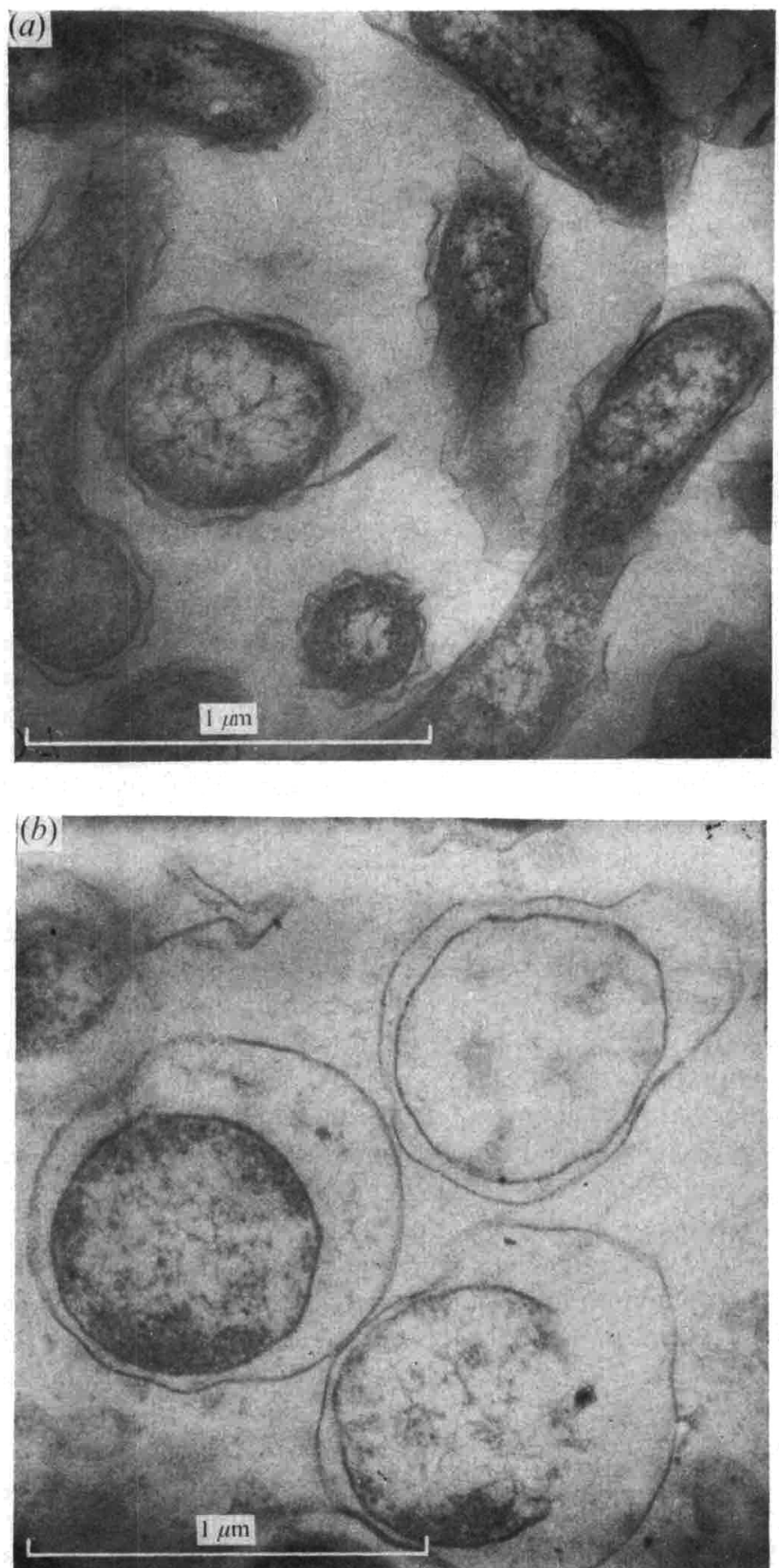

Fig. 7. (a) Section through late stationary phase organisms of Vibrio sp. NCTC4716 showing convolutions of the lipopolysaccharide-lipoprotein outer layer of wall. (b) Section through decline phase spheres of Vibrio sp. NCTC 47I6 showing that the outer layer of the wall is detached from the cell. 
Desulfovibrio aestuarii (Levin \& Vaughn, 1968) have also been reported to be not viable. Das \& Chatterjee (1969) reported that more than one rounded protoplasmic body could be formed within a spherical form of $V$. cholerae and a similar phenomenon has been reported for $V$. marinus which produces spheres containing three or four protoplasts (Felter, Colwell \& Chapman, 1969); no results were presented to show whether these spheres were viable. In contrast, in work with sections and slide culture we found only one protoplast within each sphere of Vibrio 4716; each rod appeared to give rise to a single sphere. Clark-Walker (1969) suggested that spherical cells, which he called microcysts, of Spirillum itersonii were formed as the result of the induction of a defective phage. However, using Clark-Walker's technique Baker (I97I) did not produce spheres or phage particles in cultures of Vibrio 47I 6 by treatment with mitomycin $\mathrm{C}$, indicating that such an explanation was not satisfactory for occurrence of spheres in cultures of Vibrio $47 \mathrm{I} 6$.

The peptidoglycan of Vibrio 4716 appeared to have a structure typical of Gram-negative bacteria; loss of wall rigidity and formation of spheres was correlated with a decrease in glycan chain length and a decrease in the frequency of peptide crosslinking. Vibrios, like other bacteria, must possess enzymes whose function it is to hydrolyse regions of the cell wall during growth and division. These enzymes may exist in the cell wall in either a latent or active form similar to that proposed for the autolytic enzymes of Streptococcus faecalis (Shockman, Pooley \& Thompson, 1967; Pooley \& Shockman, 1970). The active form may be made latent by a protein repressor and an uncontrolled derepression of these enzymes may occur in vibrios during conditions of starvation. Under these conditions sufficient newly synthesized subunits are not available at the sites of enzyme activity so that the degenerative changes in the peptidoglycan occur which lead to the change in cell shape. The peptidoglycan remaining in spherical organisms is less sensitive to EDTA plus lysozyme than is that in the rods, suggesting either that surface changes have rendered the peptidoglycan layer less accessible to lysozyme or, in our opinion more likely, that portions of peptidoglycan more sensitive to an endo- $N$-acetylmuramidase have been lost during the rod to sphere transformation. Peptidoglycan linked to other wall components is less sensitive to lysozyme than is non-linked peptidoglycan (Braun \& Wolff, 1970) so it seems, therefore, that the peptidoglycan remaining in the spheres is that which is linked to other wall components. Thus, if we are correct in assuming that the 'unknown' DNP derivative is derived from DAP linked to other wall components, this would explain why peptidoglycan in walls from the spheres contained a large proportion of the 'unknown' DNP derivative.

We suggest that during the rod to sphere transformation of Vibrio 4716 the peptidoglycan not attached to other wall components is fragmented as a result of attack by an autolytic endo- $N$-acetylhexosaminidase and an autolytic endopeptidase. As the peptidoglycan layer is no longer intact, the cells become spherical and the convoluted layers of the wall straighten and expand away from the cytoplasmic membrane taking with them the remaining peptidoglycan to which they are linked.

The transformation of vibrios to non-viable spheres is different from the rod to sphere transformations that occur in Myxococcus xanthus (White, Dworkin \& Tipper, 1968) and Arthrobacter crystallopoietes (Krulwich, Ensign, Tipper \& Strominger, 1967a, b) where a reduction in the number of peptide crosslinks and, in one case, a shortening of the glycan chain lengths occur without the rigidity of the peptidoglycan layer or the viability of the organisms being lost.

We thank Mr A. Davies (Pharmaceuticals Division, Imperial Chemical Industries, Alderley Park, Cheshire) for generous help and advice on bacterial cell wall analysis, for the 
electron micrographs and for facilities for some of the cell wall work; and Mr M. Crowder for technical assistance. Financial support from I.C.I. and the University of Reading Research Board for the work done at Alderley Park is gratefully acknowledged.

\section{REFERENCES}

BAKER, D. A. (197I). The morphology of vibrios. Ph.D. thesis, University of Reading.

Blackburn, S. \& Lowther, A. G. (I95I). Separation of $\mathrm{N}$-2,4-dinitrophenylamino acids on paper chromatograms. Biochemical Journal 48, I26-1 28.

BRAULKE, H. (1933). Form und Wachstumsveränderungen bei Vibrionen. Zeitschrift für Hygiene und Infektionskrankheiten $\mathbf{x 5}, 25-46$.

BraUN, V. \& REHN, K. (I969). Chemical characterization, spatial distribution and function of a lipoprotein (murein-lipoprotein) of the Escherichia coli cell wall. The specific effect of trypsin on the membrane structure. European Journal of Biochemistry 10, 426-438.

Braun, V. \& Schwartz, U. (1969). Structure, function and biosynthesis of the rigid layer of the Escherichia coli cell wall. Journal of General Microbiology 57, iii.

BraUn, V. \& WolfF, H. (1970). The murein-lipoprotein linkage in the cell wall of Escherichia coli. European Journal of Biochemistry 14, 387-391.

Burton, K. (1956). A study of the conditions and mechanisms of the diphenylamine reaction for the colorimetric estimation of deoxyribonucleic acid. Biochemical Journal 62, 315-323.

Clark-Walker, G. D. (1969). Association of microcyst formation in Spirillum itersonii with the spontaneous induction of a defective bacteriophage. Journal of Bacteriology 97, 885-892.

Das, J. \& Chatterjee, S. N. (1969). Morphological changes in Vibrio cholerae organisms in glucose saline. Journal of General Microbiology 54, 445-450.

Davis, G. H. G. \& PARK, R. W. A. (1962). A taxonomic study of certain bacteria currently classified as Vibrio species. Journal of General Microbiology 27, I0I-I19.

Elson, L. A. \& Morgan, W. T. J. (I933). A colorimetric method for the determination of glucosamine and chondrosamine. Biochemical Journal 27, 1824-1828.

Felter, R. A., Colwell, R. R. \& Chapman, G. B. (1969). Morphology and round body formation in Vibrio marinus. Journal of Bacteriology 99, 326-335.

Finkelstein, R. A., Atthasampunna, P., Chulasamayer, M. \& Charunmethee, P. (1966). Pathogenesis of experimental cholera: biological activities of purified procholeragen A. Journal of Immunology 96 , 440-449.

Gardner, A. D. \& Venkatraman, K. V. (1935). The antigens of the cholera group of vibrios. Journal of Hygiene 35, 262-282.

GHUYSEN, J. M. (1968). Use of bacteriolytic enzymes in determination of wall structure and their role in cell metabolism. Bacteriological Reviews 32, 425-464.

Glauert, A. M. \& Thornley, M. J. (1969). The topography of the bacterial cell wall. Annual Reviews of Microbiology 23, I59-198.

Harrigan, W. F. \& McCance, E. (1966). Laboratory Methods in Microbiology. London: Academic Press.

HenRICI, A. T. (1925). A statistical study of the form and growth of the cholera vibrio. Journal of Infectious Diseases 37, 75-81.

IANNETTA, A. \& WEDGWOOD, R. J. (1967). Culture of serum-induced spheroplasts from Vibrio cholerae. Journal of Bacteriology 93, 1688-1692.

INGRAM, V. M. \& SALTON, M. R. J. (1957). The action of fluorodinitrobenzene on bacterial cell walls. Biochimica et biophysica acta 24, 9-14.

Krulwich, T. A., Ensign, J. C., Tipper, D. J. \& Strominger, J. L. (1967a). Sphere-rod morphogenesis in Arthrobacter crystallopoietes. I. Cell wall composition and polysaccharides of the peptidoglycan. Journal of Bacteriology 94, 734-740.

Krulwich, T. A., Ensign, J. C., Tipper, D. J. \& Strominger, J. L. (1967b). Sphere-rod morphogenesis in Arthrobacter crystallopoietes. II. Peptides of the cell wall peptidoglycan. Journal of Bacteriology 94, $74 \mathrm{I}-750$.

Levin, R. E. \& VAUGHN, R. H. (1968). Spontaneous spheroplast formation in Desulfovibrio aestuarii. Canadian Journal of Microbiology 14, I271-1276.

LowtHer, A. G. (I95I). Identification of N-2,4-dinitrophenylamino acids. Nature, London I67, 767-768. 
MACKIE, T. J. (1929). The group of vibrios and spirilla - classification and nomenclature - general biological characters of the cholera vibrio - relationship to allied organisms. In A System of Bacteriology in Relation to Medicine, vol. 4, pp. 340-367. Great Britain: Medical Research Council.

Mandelstam, J. \& Rogers, H. J. (1959). The incorporation of amino acids into the cell-wall mucopeptide of staphylococci and the effect of antibiotics on the process. Biochemical Journal 72, 654-662.

MANDelstam, J. \& MCQUillen, K. (1968). Biochemistry of Bacterial Growth. Oxford: Blackwell.

MorRIS, J. A. \& PARK, R. W. A. (I97I). The isolation of micro-aerophilic vibrios. Society for Applied Bacteriology Technical Series 5, 207-217.

Morse, M. L. \& CARTER, C.E. (1949). The synthesis of nucleic acids in cultures of Escherichia coli, strains B and B/r. Journal of Bacteriology 58, 317-326.

Nelson, N. (1944). A photometric adaption of the Somogyi method for the determination of glucose. Journal of Biological Chemistry 153, 375-380.

PARK, R. W. A. (1961). A note on the systematic position of Vibrio fetus. Journal of Applied Bacteriology 24, 23-26.

PARK, R. W. A. \& JEYNES, M. H. (1959). Identity of the so-called vibrios of the oral flora. Journal of Bacteriology $77,667$.

Pooley, H. M. \& Shockman, G. D. (I970). Relationship between the location of the autolysin, cell wall synthesis, and the development of resistance to cellular autolysis in Streptococcus faecalis after inhibition of protein synthesis. Journal of Bacteriology 103, 457-466.

REPASKE, R. (1958). Lysis of Gram-negative organisms and the role of versene. Biochimica et biophysica acta 30, 225-232.

RondLE, C. J. M. \& Morgan, W. T. J. (I955). The determination of glucosamine and galactosamine. Biochemical Journal 6r, 586-589.

SALton, M. R. J. (196r). Studies on the bacterial cell wall. VIII. Reaction of walls with hydrazine and with fluorodinitrobenzene. Biochimica et biophysica acta 52, 329-342.

SChocher, A. J., BAyley, S. T. \& WAtson, R. W. (1962). Composition of purified mucopeptide from the wall of Aerobacter cloacae. Canadian Journal of Microbiology 8, 89-98.

Shockman, G. D., Pooley, H. M. \& Thompson, J. S. (1967). Autolytic enzyme system of Streptococcus faecalis. III. Localization of the autolysin at the sites of cell wall synthesis. Journal of Bacteriology 94, I525-I530.

Stanier, R. Y., Palleroni, N. J. \& Doudoroff, M. (I966). The aerobic pseudomonads: a taxonomic study. Journal of General Microbiology 43, 159-27I.

Strange, R. E., Dark, F. A. \& Ness, A. G. (I96I). The survival of stationary phase cells of Aerobacter aerogenes stored in aqueous suspension. Journal of General Microbiology 25, 6I-76.

Strominger, T. L. \& Ghuysen, J. M. (1967). Mechanisms of enzymatic bacteriolysis. Science, New York I56, 213-22I.

Tipper, D. J., Strominger, J. L. \& Ensign, J. L. (1967). Structure of the cell wall of Staphylococcus aureus, strain Copenhagen. VII. Mode of action of the bacteriolytic peptidase from Myxobacter and the isolation of intact cell wall polysaccharides. Biochemistry 6, 906-920.

White, D., DWorkin, M. \& TIPPER, D. J. (1968). Peptidoglycan of Myxococcus xanthus: structure and relation to morphogenesis. Journal of Bacteriology 95, 2186-2197.

WoRK, E. (1957). Reaction of ninhydrin in acid solution with straight chain amino acids containing two amino groups and its application to the estimation $\alpha$ - $\epsilon$-diaminopimelic acid. Biochemical Journal 67, 416-423. 